\title{
Princípios partilhados nas mudanças empreendidas no Ensino Médio em São Paulo e Mato Grosso
}

\author{
Principles shared in the changes made in High School in \\ São Paulo and Mato Grosso
}

Ana Lara CASAGRANDE'

Kátia Morosov ALONSO²

\begin{abstract}
Resumo
Este trabalho analisa a verossimilhança ideológica entre os projetos de reconfiguraçáo do Ensino Médio nos estados de São Paulo e Mato Grosso. O Ensino Médio é a última etapa da Educação Básica no Brasil e tem sido alvo central das políticas educacionais. A referida pesquisa envolveu um estudo exploratório, de abordagem qualitativa, cuja técnica de sistematizaçáo dos dados recorreu à análise de conteúdo. Os resultados indicam que os estados em análise, quanto à implantaçáo da Escola de Período Integral e Escola Plena, possuem efetivamente um eixo comum, enviesado pelo modelo de Escolas de Ensino Médio em Tempo Integral de Pernambuco.
\end{abstract}

Palavras-chave: Ensino Médio. Tempo integral. Política educacional.
Abstract

This work analyzes the ideological common point among projects aimed at the reconfiguration of High School in the states of São Paulo and Mato Grosso. High School is the last stage of Basic Education in Brazil and has been the central target of educational policies. This research involved an exploratory study, with a qualitative approach, whose data systematization technique involved content analysis. The results indicate that the analyzed states, regarding the implementation of the School of Integral Period and Full School, effectively have a common axis, skewed by the model of High Schools in Integral Time of Pernambuco.

Keywords: High School. Full time. Educational politics.

1 Mestre, doutora e pós-doutora em Educação. Professora Adjunta da Universidade Federal do Mato (UFMT - campus Cuiabá), Departamento de Ensino e Organização Escolar (DEOE). Participante do Grupo de pesquisa Laboratório de Estudos sobre Tecnologias da Informação e Comunicaçáo na Educaçáo (Lêtece). Endereço profissional: Av. Fernando Corrêa da Costa, no 2367 - Bairro Boa Esperança. Cuiabál MT, CEP 78060-900. Fone (65) 3615-8000. E-mail: analaracg@gmail.com.

2 Mestre e doutora em Educação. Professora Associada da Universidade Federal do Mato Grosso (UFMT - campus Cuiabá), Departamento de Ensino e Organização Escolar (DEOE), Campus Cuiabá. Líder do Grupo de pesquisa Laboratório de Estudos sobre Tecnologias da Informação e Comunicação na Educação (Lêtece). Endereço profissional: Av. Fernando Corrêa da Costa, no 2367 - Bairro Boa Esperança. Cuiabá/ MT, CEP 78060-900. Fone (65) 3615-8000. E-mail: katia.ufmt@gmail.com.

R. Educ. Públ.
Cuiabá v. 28

n. 69 p. $583-599$ set./dez. 2019 


\section{Introdução}

Este trabalho traz reflexóes da pesquisa de pós-doutorado, financiada pelo Programa Nacional de Pós-Doutorado (PNPD/CAPES), cujo objetivo foi identificar, caracterizar e analisar a verossimilhança ideológica entre os projetos voltados à reconfiguração do Ensino Médio nos estados de São Paulo e Mato Grosso.

Tratou-se de um estudo exploratório, de abordagem qualitativa, cuja técnica de sistematização dos dados envolveu a análise de conteúdo, que, segundo Bardin (1969), envolvia percorrer as fases de pré-análise (na qual se sistematizam as ideias iniciais), exploração do material e tratamento dos resultados (envolve a exploração do material com a definição de categorias, identificação das unidades de registro e das unidades de contexto nos documentos), inferência e interpretação (na qual se condensam e destacam as informaçôes para análise, culminando nas interpretaçôes inferenciais).

O Ensino Médio está estabelecido legalmente como a última etapa da Educação Básica no Brasil, segundo a Lei de Diretrizes e Bases da Educação Nacional (LDB), e tem como finalidade: a consolidação e o aprofundamento dos conhecimentos adquiridos no ensino fundamental, possibilitando o prosseguimento de estudos; a preparação básica para o trabalho e a cidadania do educando; o aprimoramento do educando como pessoa humana; a compreensão dos fundamentos científico-tecnológicos dos processos produtivos, relacionando a teoria com a prática, no ensino de cada disciplina (art. 35, BRASIL, 1996). A Constituição Federal prevê a progressiva universalização do ensino médio gratuito (art. 208, II, BRASIL, 1988), o que lembra uma problemática relacionada a essa etapa que tem altos índices de evasão dentre os jovens provenientes de famílias pobres, enquanto para jovens de grupos sociais privilegiados cursar o Ensino Médio é óbvio (GENTILI, 1996).

Tal proposta de reestruturação do Ensino Médio materializada nos estados de São Paulo e Mato Grosso está direcionada a algumas escolas e traz alterações, como: extensão da carga horária, remuneração diferenciada aos professores, dedicação exclusiva como sistema laboral, desenvolvimento do protagonismo juvenil e inserção de disciplinas eletivas. Os projetos receberam os nomes de Escola de Período Integral (EPI), no estado de São Paulo, e Escola Plena, no estado de Mato Grosso. Desse modo, o levantamento documental foi a principal estratégia metodológica utilizada para captar as tendências, nos estados supracitados, referentes às mudanças propostas para alavancar o Ensino Médio público.

A educação, de maneira geral, foi afetada pelas políticas públicas adotadas no país nos últimos anos, sob a égide da ideia de que a gestão idealizada do 
setor privado conduziria à melhora da qualidade dos serviços públicos. No entanto, para as diversas áreas, os impactos foram ainda mais profundos após o impeachment da presidente Dilma Rousseff, pois foram aprovadas alteraçóes nas políticas públicas que envolviam propostas derrotadas nas urnas no ano de 2016, "submetendo o país aos interesses do mercado financeiro internacional, o que acarreta a desindustrialização e o retorno à chamada 'vocação agrícola do Brasil'” (SAVIANI, 2018, p. 5, grifos do autor). Tratando da educação, Saviani (2018) considera as reformas empreendidas pelo atual governo regressivas, resgatadoras do espírito autoritário, marca do período da ditadura militar.

Uma das etapas alvo das reformas às quais o autor se refere é o Ensino Médio, considerada uma etapa desafiadora em termos de políticas públicas, dados os problemas a ele relacionados, em termos de permanência e evasão. Ele está estabelecido legalmente como a última etapa da Educação Básica no Brasil, segundo a Lei de Diretrizes e Bases da Educação Nacional (LDB) e tem como finalidade: a consolidação e o aprofundamento dos conhecimentos adquiridos no ensino fundamental, possibilitando o prosseguimento de estudos; a preparaçáo básica para o trabalho e a cidadania do educando; o aprimoramento do educando como pessoa humana; a compreensão dos fundamentos científicotecnológicos dos processos produtivos, relacionando a teoria com a prática, no ensino de cada disciplina (art. 35, BRASIL, 1996).

Especificamente sobre a reforma do Ensino Médio, Saviani (2018, p.7) considera que foi autoritária, dado que "baixada por medida provisória, sem sequer dar conhecimento prévio às Secretarias de Educação e aos Conselhos Estaduais de Educação que, pela Constituição e pela LDB são os responsáveis pela oferta pública desse nível de ensino.” A Medida Provisória está prevista na Constituição Federal de 1988, art. 62, para casos de "relevância e urgência", devendo-se ressaltar que tem força de lei, devendo ser submetida de imediato ao Congresso Nacional. Seu prazo de vigência é de 60 dias, prorrogáveis uma vez por igual período. Caso não seja aprovada no prazo de 45 dias, contados da sua publicação, a MP tranca a pauta de votaçóes da Casa em que se encontrar (Câmara ou Senado) até que seja votada (BRASIL, 1988).

Da mesma maneira antidemocrática, Saviani $(2018$, p.7) analisa que:

[...] vêm sendo tomadas as medidas relativas ao Plano Nacional de Educação e à realização da próxima Conferência Nacional de Educação intervindo no Fórum Nacional de Educaçáo à revelia do que dispóe a lei 13.005, de 25 de junho de 2014, que aprovou o Plano Nacional de Educação 2014-2024. Esse caráter autoritário se faz 
presente, ainda, no movimento "escola sem partido", merecidamente chamado de "lei da mordaça", pois explicita uma série de restriçóes ao exercício docente negando o princípio da autonomia didática consagrado nas normas de funcionamento do ensino.

Tecido o viés crítico do qual está revestida a análise, apresenta-se o contexto no qual está inserido o Ensino Médio brasileiro, para posteriormente pensar as alteraçóes propostas e seus impactos em realidades distintas em um país diversificado como o Brasil, inclusive com impactos para o currículo.

\section{Desenvolvimento}

\subsection{Alterações no Ensino Médio}

As discussões em torno de uma proposta de reformulação no Ensino Médio tomaram forma, então, recentemente, via Medida Provisória n. $.^{\circ} 746 / 2016$, alterada na comissão mista e na Câmara dos Deputados. Tal MP foi aprovada no Senado, sob a forma do Projeto de Lei de Conversão n. ${ }^{\circ} 34 / 2016$. O relator da matéria, senador Pedro Chaves (PSC-MS), acolheu parcial ou totalmente 148 das 568 emendas apresentadas. Posteriormente a esse contexto, foi sancionada no seguinte ano (2017) como a Lei n. ${ }^{\circ} 13.415$, de 16 de fevereiro de 2017, instituindo a Política de Fomento à Implementação de Escolas de Ensino Médio em Tempo Integral, por meio da alteração da LDB, do Fundo de Manutenção e Desenvolvimento da Educação Básica e de Valorização dos Profissionais da Educação (FUNDEB), da Consolidação das Leis do Trabalho (CLT), do Decreto-Lei n. ${ }^{\circ} 236$, de 28 de fevereiro de 1967, que versa sobre telecomunicação e radiodifusão; por fim, revogando a Lei n. ${ }^{\circ} 11.161$, de 5 de agosto de 2005, que trata do ensino de Língua Espanhola.

As alterações envolvem: ampliação da carga horária mínima anual, que será de 800 horas para o Ensino Fundamental e para o Ensino Médio, sendo que para a última etapa tal carga horária deverá ser ampliada progressivamente para 1.400 horas, devendo os sistemas de ensino oferecer, no prazo máximo de 5 anos, pelo menos 1.000 horas anuais de carga horária, a partir de 2 de março de 2017.

3 "A escola sem partido se origina de partidos situados à direita do espectro político, com destaque para o PSC (Partido Social Cristão) e PSDB secundados pelo DEM, PP, PR, PRB e os setores mais conservadores do PMDB. Como se vê, a 'escola sem partido' é, de fato, uma escola de partido. É a escola dos partidos da direita, os partidos conservadores e reacionários." (SAVIANI, 2018, p.8). 
Fica estabelecido que à Base Nacional Comum Curricular (BNCC) serão destinadas não mais que 1.800 horas do total da carga horária do Ensino Médio. Ela definirá direitos e objetivos de aprendizagem para essa etapa da Educação Básica, conforme diretrizes do Conselho Nacional de Educação, nas áreas do conhecimento: I - linguagens e suas tecnologias; II - matemática e suas tecnologias; III - ciências da natureza e suas tecnologias; IV - ciências humanas e sociais aplicadas. Desse modo, o currículo do Ensino Médio será composto pela BNCC e por itinerários formativos divididos nas áreas descritas, acrescida a formação técnica e profissional. A Lei estabelece que os sistemas de ensino possibilitem ao aluno concluinte do Ensino Médio cursar mais um itinerário formativo, mediante disponibilidade de vagas na rede (BRASIL, 2017a).

A oferta de formação com ênfase técnica e profissional considerará, segundo a Lei n. $^{\circ} 13.415$, de 16 de fevereiro de 2017, a inclusão de vivências práticas de trabalho no setor produtivo ou em ambientes de simulação, por meio de parcerias e fazendo uso, quando aplicável, de instrumentos estabelecidos pela legislação sobre aprendizagem profissional; há a possibilidade de concessão de certificados intermediários de qualificação para o trabalho, quando a formaçáo for estruturada e organizada em etapas com terminalidade (aprovada previamente pelo Conselho Estadual de Educaçáo, homologada pelo Secretário Estadual de Educação e certificada pelos sistemas de ensino) (BRASIL, 2017a).

Para cumprimento das exigências curriculares do Ensino Médio, estabelece-se que os sistemas de ensino possam reconhecer competências e firmar convênios com instituições de educação a distância com notório reconhecimento, mediante comprovação de demonstração prática, experiência de trabalho supervisionado ou outra experiência adquirida fora do ambiente escolar, entre outros (BRASIL, 2017a).

Um aspecto polêmico da Lei em destaque foi a permissão da atuação, dentro do espaço escolar, de profissionais com notório saber, ainda que estabeleça que tenham esse saber reconhecido pelos respectivos sistemas de ensino, para ministrar conteúdos de áreas afins à sua formação ou experiência profissional, atestados por titulação específica ou prática de ensino em unidades educacionais da rede pública ou privada ou das corporaçóes privadas em que tenham atuado; admite-se também a atuação de profissionais graduados que tenham feito complementação pedagógica, conforme disposto pelo Conselho Nacional de Educação.

A alteração na CLT diz respeito à alteração do art. 318, cuja redaçáo passa a ser: "O professor poderá lecionar em um mesmo estabelecimento por mais de um turno, desde que náo ultrapasse a jornada de trabalho semanal estabelecida legalmente, assegurado e não computado o intervalo para refeição.” (BRASIL, 2017a). 
Sobre o repasse de recursos, afirma-se que será realizada com base no número de matrículas cadastradas pelos Estados e pelo Distrito Federal no Censo Escolar da Educação Básica, anualmente, a partir de valor único por aluno, respeitada a disponibilidade orçamentária para atendimento, a ser definida por ato do Ministro de Estado da Educação (BRASIL, 2017a).

A Lei que institui a Política de Fomento à Implementação de Escolas de Ensino Médio em Tempo Integral, essencialmente, propóe uma ampliação de jornada, estabelece a segmentação de disciplinas de acordo com áreas do conhecimento e traz a possibilidade de inserção da opção do ensino técnico integrado à Educação Básica.

Sobre a ampliação da jornada, destacamos uma característica que pode ser atribuída a tais escolas: o caráter seletivo. A pesquisa de doutorado intitulada Gestâo pública da educação paulista: a carreira docente e o novo Ensino Médio, que analisou uma das escolas que aderiram ao Ensino Médio de Período Integral no estado de São Paulo desde a sua implantação, constatou que os jovens alunos trabalhadores foram compelidos a mudar de escola, já que se tornava inviável manter-se nela e com o seu trabalho.

Trabalho esse buscado em razão da necessidade de complementação financeira da família, em alguns casos, mas também (e possivelmente, hoje, o motivo mais evidente entre muitos jovens, consideradas as especificidades das diferentes classes sociais) da vontade de adquirir/consumir itens/objetos de desejo dos jovens do seu grupo. Ao apresentar os dados da pesquisa com jovens das periferias do Rio de Janeiro, Zaluar e Leal (2001, p.158, grifo nosso) afirmam que: "Entre os moradores da favela da Mangueira, a principal justificativa alegada para o abandono da escola é ter dinheiro próprio, constatação que se reforça com os depoimentos colhidos sobre a importância de se consumir produtos de grife".

Bourdieu (1983) também identificou o desejo de ascender o mais rapidamente possível ao estatuto de adultos e às capacidades econômicas que lhes são associadas, no caso dos filhos das classes populares. Nesse sentido, seria o novo Ensino Médio restritivo? Estaria na contramão das necessidades/ vontades dos jovens pobres?

Não é a primeira vez na história do Brasil que se promove uma reforma do Ensino Médio; dessa maneira, vale a pena recuperar brevemente um histórico do que levou (razôes não oficialmente manifestas) à aprovação Lei n. ${ }^{\circ} 5.692 / 1971$, momento em que se institucionalizava a profissionalização do Ensino Médio. Segundo Cunha (1977), uma das providências tomadas pelo governo para assumir o controle da situação de alta demanda pelo Ensino Superior foi investir no: 
[...] ensino médio distorcido, pois se ele preparasse para o trabalho, diminuiria a demanda dos que se candidatassem à universidade; além disso, um número excessivo de técnicos de nível médio que procuram o ensino superior (entendemos este ponto como distorção no dimensionamento das matrículas entre cursos técnicos de nível médio, fazendo com que haja casos de distorçôes na oferta de profissionais nas várias especialidades técnicas). (CUNHA, 1977, p.143).

Os novos contornos dados ao Ensino Médio fazem ressurgir as discussóes quanto à: natureza do seu objetivo central; fazer-se algo efetivo voltado a resolver os problemas dessa etapa; educação pública vs. privada. Pensar tais questóes no contexto atual da política e dos efeitos que ela tem apresentado na educação brasileira é ainda mais desafiador.

Um dos desafios pode ser dimensionado pelo caminho a ser percorrido para cumprir as metas estabelecidas pela Lei n. ${ }^{\circ}$ 13.005/2014, chamada de Lei do PNE. Tais metas envolvendo a melhora da educação no país (e as estratégias para cumpri-las) são estabelecidas para um prazo de 10 anos. Sobre o Ensino Médio (Meta 3), pretendia-se universalizar, até o ano de 2016, o atendimento escolar para toda a população de 15 a 17 anos e elevar, até o final do período de vigência deste PNE (2024), a taxa líquida de matrículas no Ensino Médio para 85\%.

Já em se tratando do Ensino em tempo integral, a meta envolvia oferecê-la, no mínimo, em $50 \%$ das escolas públicas, de forma a atender, pelo menos, $25 \%$ dos(as) alunos(as) da educação básica (BRASIL, 2014).

Segundo o Censo Escolar da Educação Básica 2016 - Notas estatísticas (BRASIL, 2017b), o número de matrículas no Ensino Médio, conforme a tabela 2 mostra, corresponde a um total de 8.131.988. Um número inferior ao apontado pelo Censo correspondente ao ano de 2010, de 8.357.675 (BRASIL, 2010), como é possível verificar na tabela 1.

Tabela 1 - Número de Matrículas de Educação Básica Brasil - 2010

\begin{tabular}{|c|c|c|c|c|c|c|c|c|c|}
\hline \multirow[b]{3}{*}{ Total Geral } & \multirow[b]{3}{*}{ Creche } & \multicolumn{8}{|c|}{ Matrículas de Educação Básica - 2010} \\
\hline & & \multirow[b]{2}{*}{ Pré-Escola } & \multicolumn{3}{|c|}{ E. Fundamental Regular } & \multirow[b]{2}{*}{$\begin{array}{l}\text { Ensino } \\
\text { Médio }\end{array}$} & \multicolumn{2}{|c|}{ Ed. de Jovens e Adultos } & \multirow[b]{2}{*}{$\begin{array}{l}\text { Educação } \\
\text { Profissional }\end{array}$} \\
\hline & & & Total & Anos Iniciais & Anos Finais & & $\begin{array}{c}\text { Fundame } \\
\text { ntal }\end{array}$ & Médio & \\
\hline 51.549 .889 & 2.064 .653 & 4.692 .045 & 31.005 .341 & 16.755 .708 & 14.249 .633 & 8.357 .67 & 2.860 .230 & 1.427 .004 & 924.670 \\
\hline
\end{tabular}


Vale ressaltar, ainda, o Ensino Médio oferecido em outras modalidades, como a Educação de Jovens e Adultos (EJA), correspondendo na etapa relativa ao Ensino Médio a 1.427.004 matrículas. A LDB, em vigência, traz a EJA como modalidade da Educação Básica, na Seção V, destacando-a como direcionada aos jovens e adultos que não tiveram acesso ou continuidade de estudos no Ensino Fundamental e Médio na idade própria (art. 37); afirma que os sistemas de ensino devem assegurar gratuitamente aos jovens e aos adultos, que não puderam efetuar os estudos na idade regular, oportunidades educacionais apropriadas, consideradas as características do alunado, seus interesses, condiçōes de vida e de trabalho, mediante cursos e exames $\left(\$ 1^{\circ}\right)$; e define como incumbência do poder público estimular o acesso e a permanência do trabalhador na escola ( $\left.\$ 2^{\circ}\right)$ (BRASIL, 1996).

Há, na LDB, a abertura para a matrícula compulsória de jovens maiores de 14 anos de idade nessa modalidade de ensino, como forma de aligeiramento de estudos, distorcendo o verdadeiro sentido da EJA (CONCEIÇÃO, 2015).

Já na tabela 2, é possível verificar, além do número total de matrículas, sua quantidade no que tange à etapa final da Educação Básica distribuídas por escolas, quanto à geografia: urbanas ou rurais, quanto ao período: diurno ou noturno, e, por fim, quanto à natureza: públicas (federal, estadual, municipal) ou privadas de ensino (BRASIL, 2017c). De igual forma, vê-se a quantidade de matrículas em tempo integral.

Tabela 2 - Matrícula no Ensino Médio - Brasil - 2016

\begin{tabular}{|c|c|c|c|c|c|c|c|c|}
\hline \multirow{3}{*}{$\begin{array}{l}\text { Unidade de } \\
\text { agregaçào }\end{array}$} & \multicolumn{8}{|c|}{ Matricula } \\
\hline & \multirow[b]{2}{*}{ Total } & \multicolumn{5}{|c|}{ Sétie } & \multirow{2}{*}{$\begin{array}{c}\text { Alunos } \\
\text { incluidos }\end{array}$} & \multirow{2}{*}{$\begin{array}{l}\text { Em tempo } \\
\text { integral }^{2}\end{array}$} \\
\hline & & 11 & 21 & 39 & 41 & $\begin{array}{c}\text { Nä。 } \\
\text { seriada } \\
\end{array}$ & & \\
\hline Total & 8.131 .988 & 3.175 .848 & 2.572 .609 & 2.270 .875 & 72.126 & 40.530 & 74.007 & 518.661 \\
\hline Urbana & 7.775 .050 & 3.032 .893 & 2.462 .635 & 2.175 .518 & 69.668 & 34.336 & 71.142 & 471.212 \\
\hline Rural & 356.938 & 142.955 & 109.974 & 95.357 & 2.458 & 6.194 & 2.865 & 47.449 \\
\hline Diurne & 6.309 .556 & 2.625 .984 & 1.994 .821 & 1.630 .093 & 32.495 & 26.163 & 62.389 & \\
\hline Noturno & 1.822 .432 & 549.864 & 577.788 & 640.782 & 39.631 & 14.367 & 11.618 & \\
\hline Pública & 7.117 .841 & 2.825 .636 & 2.235 .101 & 1.951 .367 & 70.004 & 35.733 & 68.892 & 480.052 \\
\hline Federal & 171.447 & 66.914 & 44.776 & 34.995 & 11.524 & 13.238 & 1.299 & 66.730 \\
\hline Estadual & 6.896 .722 & 2.740 .379 & 2.174 .983 & 1.902 .260 & 57.344 & 21.756 & 67.022 & 411.394 \\
\hline Municipal & 49.672 & 18.343 & 15.342 & 14.112 & 1.136 & 739 & 571 & 1.928 \\
\hline Privada & 1.014 .147 & 350.212 & 337.508 & 319.508 & 2.122 & 4.797 & 5.115 & 38.609 \\
\hline
\end{tabular}

Fonte: BRASIL/MEC/Inep

Nota: 1) Alunos com deficiência, transtorno global do desenvolvimento ou altas habilidades matriculados em classes comuns do ensino regular; 2) Tempo de permanência na escola igual ou superior a 7 (sete) horas diárias (calculado somando-se a duração da escolarização com a duração da atividade complementar). 
O número total da população fora da escola no ano de 2017 era de 1.543 .713 jovens brasileiros de 15 a 17 anos, o que mostra que o objetivo de universalizar o acesso até o ano de 2016 não foi cumprido. Além disso, o Censo indica que o Ensino Médio possui as menores taxas de aprovação da Educação Básica. No entanto, essa etapa de ensino apresentou uma recuperaçáo do nível de matrícula no último ano (2016), com um crescimento de 0,7\% (BRASIL, 2017b).

Algumas das 14 estratégias estabelecidas para atingir as metas estabelecidas no Plano Nacional de Educação em vigência envolvem: institucionalizar o programa nacional de renovação do Ensino Médio, a fim de incentivar práticas pedagógicas com abordagens interdisciplinares estruturadas pela relação entre teoria e prática; elaboração, pelo Ministério da Educação, em articulação e colaboração com os entes federados e ouvida a sociedade, de proposta de direitos e objetivos de aprendizagem e desenvolvimento para o Ensino Médio, com vistas a garantir formaçáo básica comum; pactuar entre União, estados, Distrito Federal e municípios a implantação dos direitos e objetivos de aprendizagem e desenvolvimento, que configurarão a $B N C C$; fomentar a expansáo das matrículas gratuitas de Ensino Médio integrado à educaçáo profissional, observando-se as peculiaridades das populaçóes do campo, das comunidades indígenas e quilombolas e das pessoas com deficiência; promover a busca ativa da população de 15 a 17 fora da escola, em articulaçáo com os serviços de assistência social, saúde e proteção à adolescência e à juventude; e implementar políticas de prevenção à evasáo motivada por preconceito ou quaisquer formas de discriminaçáo, de modo a criar uma rede de proteçáo contra formas associadas de exclusão (BRASIL, 2014).

A Meta de número 7 traz o objetivo de fomentar a qualidade da educaçáo básica em todas as etapas e modalidades, com melhoria do fluxo escolar e da aprendizagem, de modo a atingir médias nacionais específicas para o Ideb, com relação ao Ensino Médio. Assim:

Tabela 3 - Média ideal IDEB - PNE 2014-2024

\begin{tabular}{l|c|c|c|c}
\hline \multirow{2}{*}{ IDEB } & 2015 & 2017 & 2019 & 2021 \\
\cline { 2 - 5 } & 4,3 & 4,7 & 5,0 & 5,2 \\
\hline
\end{tabular}

Fonte: BRASIL, 2014, p.61.

É possível observar que a meta até o ano de 2021 é ambiciosa, dados os problemas a serem enfrentados no Ensino Médio, inclusive com relação a financiamento, e o fato de haver uma conjuntura político-econômica desfavorável para os investimentos em serviços públicos. O presidente Michel Temer aprovou a 
Proposta de Emenda Constitucional (PEC) aprovada na Câmara dos Deputados e no Senado, que congela as despesas do Governo Federal com saúde e educação, com cifras corrigidas pela inflação, pelo período de até 20 anos. Na prática, funciona da seguinte maneira: o limite das despesas será o gasto do ano anterior corrigido pela inflação, isso é, na comparaçáo do que o dinheiro é capaz de comprar em dado momento, fica praticamente inalterado, por isso, se fala em congelamento. A justificativa do governo é de que a mudança fiscal ajude na contenção do rombo nas contas públicas. Ainda que a economia volte a crescer, o Estado terá a limitação na aplicação de recursos em setores imprescindíveis, como a educação.

$\mathrm{O}$ que intriga é a meta de ampliar o Ensino Integral, que tem um valor de ponderação maior no FUNDEB, em um cenário de congelamento de gastos. Além de trazer para o Ensino Médio uma necessidade de investimentos grande para operacionalizar a inserção da formação técnica, em termos estruturais e de pessoal.

Os estados em análise neste trabalho têm características bastante distintas em termos territoriais e econômicos, por isso, faz-se uma breve contextualização sobre elas, a seguir. Lembramos que as informaçóes foram extraídas dos endereços eletrônicos oficiais dos estados.-No caso de Mato Grosso, a fonte central foi o site do próprio governo e, no caso de São Paulo, o portal de estatísticas da Fundação Sistema Estadual de Análise de Dados (SEADE).

O estado de Mato Grosso está localizado no Centro-Oeste brasileiro, tem 903.357,908 km2 de extensão, sendo o terceiro maior estado do país. Sua capital é Cuiabá. É um estado com altitudes modestas, o relevo apresenta grandes superfícies aplainadas, talhadas em rochas sedimentares e abrange três regiōes distintas: na porção centro-norte do estado, a dos chapadóes sedimentares e planaltos cristalinos (com altitudes entre 400 e $800 \mathrm{~m}$ ), que integram o planalto central brasileiro. A do planalto arenito-basáltico, localizada ao sul, simples parcela do planalto meridional. A parte do Pantanal Mato-Grossense, baixada da porçáo centro-ocidental.

Devido à grande extensão Leste-Oeste, o território brasileiro abrange quatro fusos horários situados a oeste de Greenwich. O estado de Mato Grosso abrange o fuso horário quatro negativo (-4). Apresenta, portanto, 4 horas a menos, tendo como referência Londres, o horário Greenwich Meridian Time (GMT).

Segundo o último levantamento do Instituto Brasileiro de Geografia e Estatística (IBGE) realizado em 2010, Mato Grosso possui 3.035.122 habitantes, o que representa $1,59 \%$ da população brasileira. Vivem na zona urbana $81,9 \%$ da população e $18,1 \%$ da zona rural. O número de homens corresponde a $51,05 \%$, sendo ligeiramente superior ao das mulheres, que representa 48,95\% (MATO GROSSO, 2018 [on line]).

Já o estado de São Paulo está localizado na região Sudeste, com 248.219,63 km2 de extensão e conta com 645 municípios. Sua capital é a cidade de São 
Paulo. Em termos econômicos, São Paulo é o estado mais rico do país, com uma maior presença de indústrias e uma maior diversidade em atividades produtivas, sendo responsável por 28,7\% pelo PIB brasileiro (SEADE, 2018 [on line]).

O território do estado abrange os Planaltos e chapadas da bacia do Paraná, a oeste; a leste, os Planaltos e serras do Atlântico leste-sudeste, e, entre eles, a Depressão periférica da borda leste da bacia do Paraná. Há também, na região próxima ao mar, uma planície litorânea, que é limitada pela Serra do Mar. O ponto mais alto é a Pedra da Mina, com 2.798 metros acima do nível do mar, localizada na Serra da Mantiqueira.

O estado de São Paulo segue o horário de Brasília (UTC-3) e adere ao horário de verão entre outubro e fevereiro, quando os relógios são adiantados em uma hora (UTC-2).

Conforme a projeção populacional de 2016, da Fundação SEADE, com base na população de 43.359.005 habitantes, o estado de São Paulo tem 21.100.483 homens e 22.258 .422 mulheres, dos quais $96,32 \%$ da população total vivem na zona urbana e 3,681\% na zona rural (SEADE, 2018 [on line]).

\subsection{Currículo como instância de poder}

É importante constatar que um currículo escolar não surge por acaso. Ele se materializa em um documento, mas vai além, encerrando as finalidades da formaçáo da pessoa que se espera da escola. Nesse cenário de proposta de mudanças, vale reiterar que a educação deve ser compreendida em conexấo com a sociedade de modo geral. Nesse sentido, Apple (2002, p. 24) aponta o quão importante é refletir sobre

[...] o conhecimento que transmitimos, as relaçóes sociais que dominam as salas de aula, a escola como mecanismo de preservação e distribuição cultural e econômica e, por fim, nós próprios, enquanto pessoas que trabalham em tais instituiçôes, no contexto em que todos se encontram. Tais elementos encontram-se sujeitos a uma interpretação dos respectivos lugares numa sociedade complexa, estratificada e desigual. Contudo, devemos ser prudentes, não utilizando uma forma imprópria essa tradição de interpretação.

A cautela a qual o autor se refere residiria no fato de fugir do mecanicismo e entender que a manipulação consciente de escolarização por um determinado grupo com poder ocorre, mas a questão é bem mais complexa do que parece 
à primeira vista. Para ele, "uma das chaves para a compreensão desta questão encontra-se no conceito de hegemonia." (APPLE, 2002, p. 25). Para compreendêlo, Apple (2002) se apoia na análise de Raymond Willians, ao mesmo tempo em que reconhece o desenvolvimento aprofundado do conceito por Gramsci, cuja posição indica que a hegemonia está relacionada a um grupo organizado de significados e práticas, perpassados por um sistema de significações central. Nesse sentido, as escolas funcionariam como "agentes da hegemonia cultural e ideológica, segundo Willians, como agentes da tradição selectiva e da 'incorporação' cultural." (APPLE, 2002, p. 28).

Apple (2002) aborda a necessidade de descolonizar o currículo, o que significa dizer que o currículo está permeado pelo ponto de vista dos grupos dominantes. Trazer as experiências, vivências e contextos dos estudantes seria importante: "A parcialidade dos materiais existentes não deveria existir como matéria-prima apenas para as análises feitas por teses e dissertações acadêmicas [...], mas poderia servir de ponto de partida para estratégias de descolonização no próprio centro da atividade pedagógica e curricular", conforme Silva (1996, p. 70).

Silva (1996, p. 61) ressalta aspectos importantes a respeito do currículo:

[...] o caráter inescapavelmente político da educação e do currículo; as conexóes entre os processos educacionais e as relaçôes de classe, gênero, raça; os estreitos nexos entre conhecimento e saber, de um lado, e poder e dominação, de outro; a natureza histórica e construída das relaçôes e processos sociais e educacionais; os vínculos entre regimes e relaçóes específicas de saber-poder e a constituição e produção de identidades sociais particulares; a caracterização do saber e do currículo como um território contestado e de luta por hegemonia; o envolvimento da educação e do currículo na construção do "outro" e da alteridade.

Fernandes (1989), que apresentou a versão original para a LDB de 1996, considerou necessário fazer uma revolução a partir do topo, ou seja, por meio da educação, para acabar com a mentalidade do privilégio, e na base, para que a massa tivesse acesso ao ensino. Atualmente, a questáo do acesso parece superada, sobretudo no Ensino Fundamental, obrigatório, cujos índices indicam a universalização da educação na idade correspondente à etapa. Para o Ensino Médio, como possível observar pelos dados de acesso, evasão e repetência, ainda há muito a ser feito, de modo que é possível constatar a última etapa da educação Básica como um privilégio, assim como o acesso ao Ensino Superior. Dentre três prioridades pedagógicas listadas por Fernandes (1989, p. 131), garantia de acesso 
às oportunidades educacionais e a ressignificação da escola como valor social, vista como comunidade educacional, está a "auto-emancipação pedagógica. $\mathrm{O}$ repúdio à colonização de nossa cabeça."

Algo recorrente no Brasil, com relação às propostas de reforma e ou modelos curriculares, diz respeito à importação do ideal norte-americano, sobretudo pela força dos organismos internacionais, que passaram a conceber a noção de educação como dotada de um valor econômico próprio e considerada um bem de produção (capital) e não apenas de consumo (SAVIANI, 2005, p. 22). No entanto, Fernandes (1989) já chamava a atenção desde o século passado, uma reflexão possível e necessária até hoje, para o fato de podermos tentar imitar as mudanças promovidas pelos Estados Unidos, "mas não podemos transferir para cá as condiçóes econômicas, culturais e políticas dos Estados Unidos. Infelizmente, para nós. Não temos meios para atingir os fins." (FERNANDES, 1989, p.131).

Um caminho possível, então, para o contexto educacional brasileiro passaria pela "autonomia escolar que esteja relacionada dialeticamente com a independência econômica, com a emancipação nacional e com a revolução democrática. Esses elementos são interagentes reiterativos. Não podem ser separados." (FERNANDES, 1989, p.131).

Como parte do acesso ampliado à educaçáo pública, Fernandes (1989) defendia que as instituiçôes escolares privadas coexistissem com as públicas, mas que a verba pública fosse destinada à escola pública, como parte da democratização do ensino: "Portanto, é necessário que se respeite o princípio do pluralismo educacional. Mas dele não decorre que caiba ao Estado o mecenato do financiamento do ensino privado, leigo e confessional." (p. 21). O autor esclarece ainda sobre a necessidade de que o poder público coloque o ensino ao alcance do estudante pobre e ajude-o, caso necessário, a manter-se na escola pública e gratuita.

\subsection{Projetos de Escola com Ensino Médio em Tempo Integral:} os casos de São Paulo e Mato Grosso

Os estados de São Paulo e Mato Grosso foram selecionados para a realização deste estudo por estarem, ambos, um passo à frente da aprovaçáo da Reforma do Ensino Médio, já em processo de instituição da jornada expandida em seus estados.

Fazendo a análise documental, observou-se que o estado de Pernambuco é referência para o ensino integral implementado nos estados de São Paulo e Mato Grosso. Os documentos analisados dos últimos dois estados, que apresentam as bases do novo modelo, explicitam tal referência. No documento Introdução às Bases Teóricas e Metodologias do Modelo Escola da Escola (MT), assinado pelo 
Instituto de Corresponsabilidade pela Educação (ICE), disponibilizado na página eletrônica da Secretaria de Educação de Mato Grosso, e direcionado aos professores, afirma-se que o modelo de ensino integral nasceu em Recife, no início dos anos 2000, a partir da iniciativa de um ex-aluno (não nomeado) para a revitalização do Ginásio Pernambucano. Esse ex-aluno relata: "logo reuniu outros representantes do segmento privado, como ABN AMRO Bank, CHESF, ODEBRECHT e PHILIPS.” (ICE, 2015, p. 6). Ou seja, é um modelo de escola pensado por pessoas ligadas à gestão do setor privado, por empresas. Nesse caso especificamente: um banco, uma companhia hidrelétrica, uma construtora e uma empresa de produtos voltados à tecnologia médica e de consumo. As "mudanças profundas" vislumbradas no interior da escola pública envolvem "conteúdo, método e gestão, a partir das quais se construíram as bases do Modelo da Escola da Escolha." (ICE, 2015, p. 7).

O documento Diretrizes do Programa Ensino Integral, elaborado pela Secretaria de Educação do Governo do estado de São Paulo ${ }^{4}$, apresenta sua principal referência para redesenhar a escola: "o modelo de Escolas de Ensino Médio em Tempo Integral de Pernambuco, concebido pelo Instituto de CoResponsabilidade pela Educação e implantado nas escolas estaduais da rede pernambucana desde 2004." (SÃO PAULO, 2011, p.11).

Isso posto, constata-se que os projetos de reestruturação do Ensino Médio (por meio de escolas-modelo ${ }^{5}$ ) tem um eixo teórico comum nos estados de São Paulo e Mato Grosso, perpassados pela lógica das Escolas de Ensino Médio em Tempo Integral (assim batizadas pela Secretaria Estadual de Educação), iniciada em Pernambuco.

\section{Considerações finais}

Discutir os problemas presentes e as mudanças propostas para o Ensino Médio é importante para construir uma melhor compreensão da perspectiva político-administrativa direcionada à etapa, por meio da ampliaçáo progressiva da carga horária, para 1.400 horas, e estabelecimento da BNCC, por exemplo.

Para a compreensão dos possíveis pontos comuns na implantação do (novo)

4 No documento constam agradecimentos à contribuiçấo da equipe do Instituto de Co-Responsabilidade pela Educação (ICE) pelo apoio técnico para a concepção, desenvolvimento e implantação do Programa de Ensino Integral.

5 Chamam-se escola-modelo, pois se julga importante lembrar que, mesmo no estado de Sáo Paulo, em que a experiência começou desde o ano de 2011, não foi pensada inicialmente para toda a rede. 
Ensino Médio, em tempo integral, em algumas escolas dos estados de São Paulo e Mato Grosso, baseado em novas formas de gestão do trabalho e currículo, foi possível evidenciar, pela leitura dos documentos norteadores dos programas, que se recria o modelo das escolas iniciado em Pernambuco. Desenvolver o projeto de vida do jovem é indicado como a centralidade da reestruturação das escolas de Ensino Médio nos modelos investigados, sendo que ambos os estados salientam as mudanças pelas quais a sociedade passa e a necessidade de adaptação do ambiente escolar ao novo perfil de jovem.

Observa-se, então, uma espinha dorsal teórico-metodológica, apesar de que os estados em análise neste trabalho têm características bastante distintas em termos territoriais e econômicos. Destaca-se, ainda, o protagonismo do Instituto de Corresponsabilidade pela Educação (ICE) na constituição do modelo inicial pernambucano, bem como dos que nos propusemos a analisar. $\mathrm{O}$ protagonismo de agências do mercado na administração pública pode ser visto como consequência do advento das políticas neoliberais e seus impactos sobre o olhar para a valorização da sua dinâmica administrativa.

Reiteramos, por fim, a preocupaçáo com a educaçáo do jovem pobre brasileiro, que tem um perfil diferente do privilegiado, pois para o primeiro a escola é o espaço no qual terá acesso à possibilidade de planejar e construir uma trajetória relacionada ao seu crescimento pessoal e profissional; para o segundo, cursar o ensino superior e melhorar as suas possibilidades de crescimento, nas mais variadas dimensões, inclusive financeira, é algo lógico.

\section{Referências}

APPLE, M. W. Ideologia e currículo. Porto: Porto Editora, 2002.

BARDIN, L. Análise de conteúdo. Lisboa: Ediçóes 70, 1979.

BOURDIEU, P. A “juventude” é apenas uma palavra. In: BOURDIEU, Pierre. Questóes de sociologia. Rio de Janeiro: Marco Zero, 1983. p. 112-121.

BRASIL. Constituição da República Federativa do Brasil. Brasília: Senado Federal, 1988.

BRASIL. Lei de Diretrizes e Bases. Lei n. ${ }^{\circ}$ 9.394, de 23 de dezembro de 1996. Brasília: Ministério da Educação, 1996.

BRASIL. Ministério da Educação. Inep. DEED. Censo Escolar 2010: visão geral dos principais resultados. Brasília, 20 de dezembro de 2010. 
BRASIL. Plano Nacional De Educaçáo 2014-2024. Brasília: Câmara dos Deputados, Ediçóes Câmara, 2014.

BRASIL. Política de Fomento à Implementaçáo de Escolas de Ensino Médio em Tempo Integral. Lei n. ${ }^{\circ}$ 13.415, de 16 de fevereiro de 2017. Brasília, 16 de fevereiro de 2017, 2017a.

BRASIL. Ministério da Educação. Inep. Censo Escolar da Educação Básica 2016 - Notas Estatísticas. Brasília-DF, fevereiro de 2017, 2017 b.

BRASIL. Censo Escolar da Educaçáo Básica 2016 Notas Estatísticas. Brasília, fevereiro de 2017, 2017c.

CONCEIÇÃO, L. C. da. "A alternativa para o menino indesejável": vozes e sujeitos na biopolítica da juvenilização da EJA. Anais... 37a Reunião Nacional da ANPEd, UFSC, Florianópolis, 2015, p.1-17.

CUNHA, L. A. R. da. Política educacional no Brasil: a profissionalização do Ensino Médio. Livraria Eldorado Tijuca: Rio de Janeiro, 1977.

FERNANDES, F. O desafio educacional. São Paulo: Cortez; Autores Associados, 1989.

GENTILI, P. Neoliberalismo e educação: manual do usuário. In: GENTILI, Pablo (Org.). Escola S.A.: quem ganha e quem perde no mercado educacional do neoliberalismo. CNTE: Brasília, 1996. p. 09-49.

ICE. Instituto de Corresponsabilidade pela Educação. Introdução às Bases Teóricas e Metodologias do Modelo Escola da Escolha. Recife: ICE, 1 ed. 2015.

MATO GROSSO. Geografia. Disponível em: http://www.mt.gov.br/geografia. Acesso em: 30 abr. 2018.

SÃO PAULO (Estado). Diretrizes do Programa Ensino Integral. São Paulo: Secretaria de Estado da Educação, 2011.

SAVIANI, D. Transformaçóes do capitalismo, do mundo do trabalho e da educação. In: LOMBARDI, José Claudinei; SAVIANI, Dermeval (Org.). Capitalismo, trabalho e educaçáo. $3^{\mathrm{a}}$ ed. Campinas: Autores Associados, 2005. p.13-24.

SEADE - Fundação Sistema Nacional de Análise de dados. Indicadores do estado de Sáo Paulo. Disponível em http://www.seade.gov.br/. Acesso em: 07 maio 2018. 
SILVA, T. T. da. Descolonizar o currículo: estratégias para uma pedagogia crítica. Dois ou três comentários sobre o texto de Michael Apple. In: COSTA, Marisa Vorrager (Org.). Escola básica na virada do século: cultura, política e educação. São Paulo: Cortez, 1996. p. 61-72.

ZALUAR, A.; LEAL, M. C. Violência extra e intramuros. Revista Brasileira de Ciências Sociais, v. 16, n. 45, p.145-164, fev. 2001. 